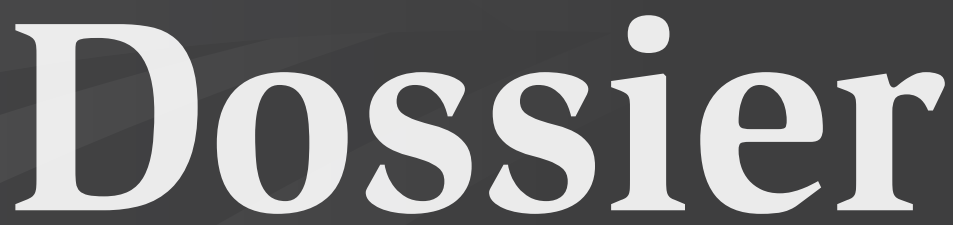

Neoextractivismo 


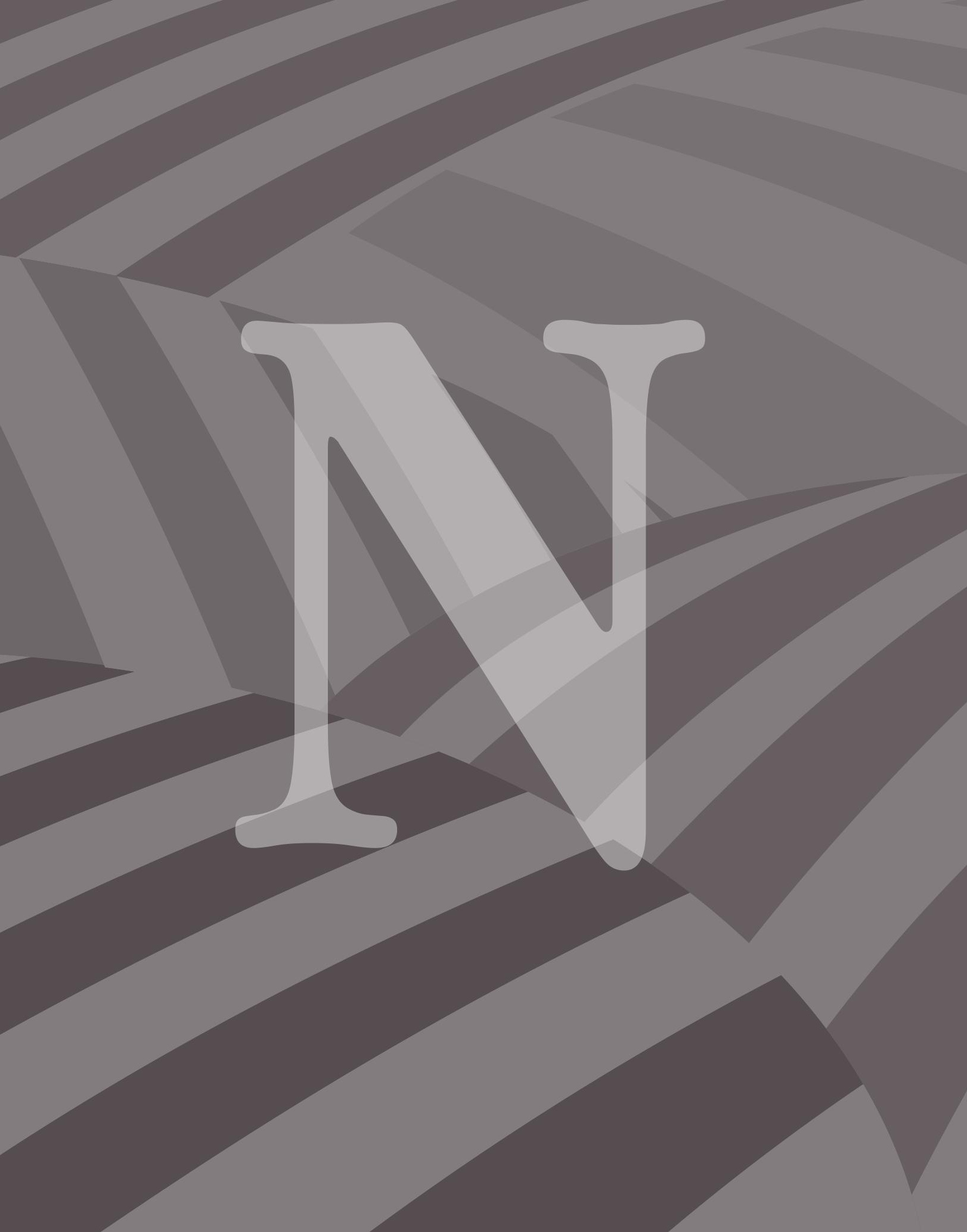




\section{Neoextractivismo en América Latina y Colombia: una reflexión desde la ecología política}

Por Carolina Arias Hurtado*

Resumen: en el artículo, se realiza una aproximación a la problemática del neoextractivismo en el siglo XXI desde la ecología política en el ámbito regional, nacional y local. En primer lugar, se presenta un panorama sobre las contradicciones del desarrollo neoextractivista en América Latina como expresión de la crisis multidimensional y la necesidad de búsqueda de alternativas. Enseguida, se examina la situación actual del neoextractivismo en Colombia, a partir del reconocimiento de los conflictos socioambientales y las luchas sociales por la justicia ambiental. Por último, se analiza el caso del municipio de Marmato (Colombia), lugar emblemático por la constante defensa del territorio como un patrimonio y un derecho.

Palabras clave: neoextractivismo, ecología política, conflictos socioambientales, justicia ambiental.

\section{Neo-extractivism in Latin America and Colombia: a political ecology reflexion}

Abstract: In this article an approach is performed to the problematic of neoextractivism in the 21st century at a regional, national and local level from the political ecology view. In the first place, it presents a panorama on the contradictions of the neo-extractivist development in Latin America, as an expression of the multidimensional crisis and the needing to search for alternatives. Next, it examines the current situation of neo-extractivism in Colombia from the

* Estudiante del doctorado en Estudios del Desarrollo de la Universidad Autónoma de Zacatecas (México). Correo electrónico: lcarias@utp.edu.co 
recognition of the social-environmental conflicts and social struggles for environmental justice. Finally, the paper analyzes the case of the municipality of Marmato (Colombia), emblematic in the defense of the territory as a heritage and a right.

Keywords: neo-extractivism, political ecology, social-environmental conflicts, environmental justice.

Cómo citar este artículo: Arias Hurtado, Carolina (2017). Neoextractivismo en América Latina y Colombia: una reflexión desde la ecología política. Revista Controversia, 208, 16-53.

Fecha de recepción: 3 de febrero del 2017

Fecha de aprobación: 27 de abril del 2017

\section{Introducción}

Tras seis décadas por las sendas del desarrollo como ideal de crecimiento económico, la realidad latinoamericana en los albores

_ del siglo Xxi devela las múltiples contradicciones de este discurso e ideología del pensamiento moderno en su versión hegemónica y de modelo civilizatorio. Como lo argumenta Cubillos Quintero (2016, p.38), "la época moderna consolidó un pretendido sentido de unidad y homogeneidad al instaurar un concepto de progreso y desarrollo" y consiguió la dicotomía existente entre naturaleza y sociedad.

Los programas de ajuste estructural acaecidos a finales del siglo XX determinaron el papel de América Latina en el nuevo orden mundial, principalmente como plataforma para la expansión geográfica de la industria maquiladora, proveedora de fuerza de trabajo y materias primas baratas. En el marco del Consenso y el Posconsenso de Washington se reestructuraron las economías de la región desde los preceptos neoliberales (privatización, libre comercio y desregulación) y se redefinió el papel del Estado para facilitar el desarrollo guiado por el mercado, es 
decir, por las inversiones privadas y extranjeras en el sector primario mediante el neoextractivismo.

De acuerdo con Harvey (2004), el neoextractivismo se ha constituido como un propósito central para evitar la parálisis del motor de la acumulación capitalista. Sin embargo, las implicaciones socioculturales, políticas, económicas y ecológicas de este modelo de desarrollo develan las múltiples contradicciones del capitalismo.

Como lo sugiere Veltmeyer (2013), tanto el estructuralismo latinoamericano y la escuela marxista de la dependencia como los economistas neoclásicos y neoliberales coinciden en que la explotación de la naturaleza a través del neoextractivismo se constituye como una vía compleja y no recomendable hacia el desarrollo.

En ese orden de ideas, la búsqueda de alternativas al desarrollo se encuentra íntimamente ligada a la búsqueda de alternativas al neoextractivismo. Igualmente, cuestionar los modos en que Asia, África y Latinoamérica han sido definidas como "subdesarrolladas”, así como discutir las bases conceptuales del desarrollo, sus instituciones y sus modos de entender la relación sociedad-naturaleza es crucial para entender ampliamente esta problemática (Escobar, 1998).

En este contexto, la ecología política reúne diversos enfoques críticos que estudian la relación sociedad-naturaleza desde dos visiones epistemológicas para investigar el desarrollo: la perspectiva materialista asociada con la economía política marxista, las teorías de la dependencia, los estudios del campesinado y la teoría del sistema-mundo, y el posestructuralismo centrado en el análisis del discurso y las dimensiones culturales de los problemas ambientales, además de los estudios de caso a nivel local, las formas cotidianas de resistencia y la historia ambiental (Tetreault, 2016). 
En el centro de la ecología política latinoamericana se encuentra el estudio de las relaciones de poder en torno a la apropiación social de la naturaleza y los conflictos socioambientales, así como el reconocimiento de las luchas sociales y los reclamos de justicia ambiental hechos por grupos subalternos (Alimonda, 2011; Leff, 2012; Martínez-Alier, 2015; Tetreault, 2016). Según Eduardo Gudynas (2011b), desde esta perspectiva teórica:

[se] defiende[n] los valores intrínsecos en la naturaleza, las valoraciones económicas (y conceptos asociados como capital natural) pierden su centralidad. El valor económico corregido de todos modos tiene sus limitaciones [...] y por ello es uno más en una amplia canasta de múltiples valoraciones. Por lo tanto, la naturaleza deja de ser mercantilizable o expresable como capital, y deberá ser abordada como un patrimonio (p.401).

Este enfoque, a su vez, devela la persistencia estructural del intercambio desigual que no considera los impactos locales generados por el neoextractivismo; así como también reconoce los conflictos socioambientales que emergen de las asimetrías estructurales de la distribución desigual de poder e ingresos y de las desigualdades sociales (MartínezAlier y Walter, 2016).

Parafraseando a Svampa (2011), el análisis de los conflictos socioambientales es una ventana privilegiada para analizar la cuestión del desarrollo neoextractivista que enfrenta intereses y visiones diferentes sobre la naturaleza, en una disputa por el control del territorio en el contexto de asimetrías de poder.

En tal sentido, el territorio debe ser concebido como una construcción sociocultural y un escenario de intereses y confrontaciones ideológicas (Lefebvre, 1974), fuente y objetivo de conflictos en el marco del desarrollo neoextractivista que pone en contacto no solo lo local y lo global, sino también las relaciones de poder entre diferentes agentes sociales. Así, el territorio es un componente clave en la construcción y renova- 
ción de la cultura desde la cual se definen los referentes identitarios y en donde, además, se gesta y se consolida la acción colectiva (Osorio, 2009).

De la misma manera, los conflictos socioambientales implican el reconocimiento de otros "procesos de valoración que van más allá de la racionalidad económica que asigna precios y costos crematísticos al medioambiente" (Martínez-Alier y Walter, 2016, p.78). En concordancia con lo anterior, la justicia ambiental surge para comprender esos procesos de valoración y los intereses que permiten la movilización de los diferentes agentes sociales: acceso a los medios de producción, empleo, distribución del ingreso (intereses materiales), pervivencia, identidad, autonomía (intereses simbólicos) (Martínez-Alier y Walter, 2016).

El objetivo de este texto es realizar una aproximación a la problemática del neoextractivismo en el siglo XXI en el ámbito regional, nacional y local desde la ecología política. La primera sección presenta un panorama actual sobre las contradicciones ecológicas, socioculturales, económicas y políticas del desarrollo neoextractivista en América Latina, como expresión de la crisis multidimensional y la necesidad de búsqueda de alternativas. La segunda parte examina la situación actual del neoextractivismo en Colombia, a partir del reconocimiento de los conflictos socioambientales emergentes y las luchas sociales por la justicia ambiental desde intereses materiales y simbólicos. Por último, se analiza el caso del municipio de Marmato (Colombia), lugar reconocido por la defensa del territorio como un patrimonio y un derecho.

Como argumento principal, se plantea que América Latina, en sus diferentes niveles territoriales (regional, nacional y local), ha sido insertada en la dinámica de acumulación capitalista a través del neoextractivismo y, en este marco, se están librando luchas de clases que buscan conservar o subvertir la lógica de este modelo. 


\section{Problemática del neoextractivismo en América Latina}

El extractivismo ha estado presente a lo largo de las grandes etapas del capitalismo. Este sistema se ha basado en el desarrollo de las fuerzas de producción y acumulación de capital por medio de la explotación de la naturaleza y su exportación en forma de mercancías primarias. No obstante, en el marco de la nueva geopolítica del capital en la región, este modelo de acumulación ha cobrado una fuerza inusitada: un nuevo extractivismo.

Si bien autores como Gudynas (2009), Petras y Veltmeyer (2017) plantean que el neo-extractivismo está asociado con los actuales "gobiernos progresistas", formados en el ciclo progresista de la política latinoamericana, coincidimos con Claudia Composto y Mina Navarro (2014) en que:

las novedades del neoextractivismo atraviesan todo el arco político de los gobiernos regionales (incluyendo a los de signo conservador como México y Colombia, entre otros), ya que responden a transformaciones sistémicas de carácter cualitativo que, por lo menos durante los últimos treinta años, configuran un escenario significativamente renovado, especialmente en sus implicancias ambientales, sociales y políticas (p.50).

Por ende, consideramos que el neoextractivismo está presente en los distintos regímenes de nuestro continente, desde los países más apegados al modelo neoliberal como México y Colombia hasta los países "posneoliberales" como Bolivia y Ecuador (Veltmeyer, 2013). La aspiración al desarrollo continúa ligada a la visión occidental de explotación intensa de la naturaleza como la histórica ventaja comparativa de la región que debe ser aprovechada ante los actuales cambios en la economía mundial. En palabras de Svampa (2011), “en el marco de un nuevo ciclo de acumulación, América Latina parece haber retomado este mito fundante y primigenio, que, en el contexto actual, alimenta nuevamente la ilusión desarrollista” (p.422). 
La perspectiva neoextractivista latinoamericana incluye megaproyectos orientados a la explotación de minerales (metálicos, fósiles, industriales, materiales de construcción), biomasa (cultivos, plantaciones, pesca) (Martínez-Alier y Walter, 2016) y fuentes de agua para la irrigación de cultivos, procesos industriales y generación de energía (grandes represas hidroeléctricas). Estos proyectos se desarrollan en el marco de los planes Integración de la Infraestructura Regional Suramericana (IIRSA) e Integración y Desarrollo Mesoamérica, los cuales contemplan la construcción de complejos sistemas de infraestructura en materia de comunicaciones, energía y transporte (hidrovías, puertos, corredores bioceánicos).

Este modelo de acumulación expresa continuidades estructurales con el proyecto de colonialidad y dependencia histórica, en cuyo marco las relaciones de producción de las naciones subordinadas de América Latina han permitido la reproducción ampliada del capital, a través de la integración al mercado mundial mediante el intercambio desigual y la superexplotación del trabajo (Marini, 1991).

La etapa actual de expansión del capitalismo se ha caracterizado por profundizar el modelo neoliberal y por permitir la recolonización político-económica y militar para la proyección de los intereses de los países hegemónicos en la región. Es así como Estados Unidos, para garantizar su estrategia de seguridad nacional y las disposiciones de la omc, el Banco Mundial y el FMI, no solo ha incidido en la política económica de los países latinoamericanos mediante los tratados de libre comercio, en condiciones desiguales, sino también en las agendas de seguridad nacional como el Plan Colombia (1999) y la Alianza para la Seguridad y la Prosperidad de América del Norte -Aspan- (2002), que le han permitido la militarización y el control de territorios estratégicos por sus riquezas naturales (petróleo, minerales, biodiversidad y agua) (Borón, 2012).

Por su parte, Canadá se ha posicionado como la principal fuente de inversión extranjera directa en el sector minero, a través de compañías 
mineras con sede en ese país y de propiedad canadiense, las cuales actúan con el apoyo del Gobierno, que juega un papel activo en el cabildeo y apoyo diplomático para obtener concesiones y licencias sociales, en el uso de recursos públicos y programas de cooperación internacional para brindar apoyo financiero a las compañías mineras, así como en el diseño de un marco global de políticas mineras (Veltmeyer, 2013) y, en algunos casos, en la formulación de la legislación minera para países como Colombia (Arias Hurtado, 2014).

En América Latina, el Estado ha coadyuvado a legitimar los intereses de clase de los agentes hegemónicos del sector extractivo - principales beneficiarios de la renta extractiva - a través de la privatización de los medios de producción y las empresas del Estado, además de la (re)primarización de sus economías, las reformas a los marcos regulatorios y la flexibilización de los controles ambientales y sociales, todo para que la inversión extranjera acceda a fuerzas de trabajo y "recursos" estratégicos baratos. Además, el control por el territorio y sus riquezas naturales se encuentra en el corazón del conflicto armado, la violencia y la represión, pues:

la guerra [...] no es solamente un problema de luchas territoriales por controles territoriales, como táctica y estrategia, sino que obedece a macroproyectos de desarrollo, donde es el futuro el que está definiendo el conflicto presente y no solo el pasado histórico de las injusticias (Sarmiento, 2000, p.26).

En consecuencia, durante las últimas dos décadas se han incrementado los conflictos socioambientales relacionados con el neoextractivismo en América Latina, mientras "su verdadero aporte al desarrollo nacional es debatido” (Gudynas, 2011a, p.379).

El Atlas de Justicia Ambiental (EJOLT, 2016) identificó 338 conflictos causados por el neoextractivismo en once países de América Latina. Dichos conflictos están relacionados con la exploración y explotación de 
oro, minerales y materiales de construcción; actividades de producción de biomasa y conflictos de tierras, así como explotación de hidrocarburos. Las comunidades indígenas están presentes en la mitad de los conflictos. Del total de los conflictos, Colombia registra el mayor número (88), seguido por Brasil (58), Ecuador (48), Argentina (32), Perú (31), Chile (30), México (19), Bolivia (13), Panamá (7), Costa Rica (6) y Guatemala (6) (ver gráfico 1). Por su parte, en el año 2017, el Observatorio Latinoamericano de Conflictos Mineros -Ocmal- registró 217 conflictos solamente por proyectos mineros que afectan a 331 comunidades de la región.

\section{Gráfica 1. Conflictos socioambientales por el neoextractivismo en América Latina}

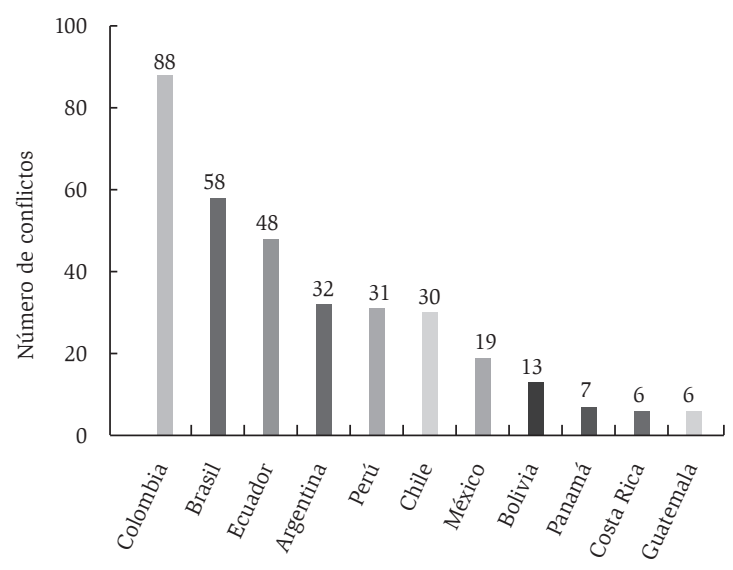

Fuente: Elaboración propia con datos de EJOLT (2016)

Según James O’Connor (2003):

en la economía capitalista la 'naturaleza' es el punto de partida de la producción, pero no suele ser el punto de retorno [...] El agotamiento y la destrucción de los recursos y la contaminación dependen el uno del otro; son el resultado necesario del mismo proceso universal de 'valorización' del capital ( p.14). 
En todos los casos el neoextractivismo genera altos impactos ecológicos y se constituye como un factor determinante del deterioro de ecosistemas sensibles - tanto en intensidad como en cobertura-: cumbres cordilleranas, selvas tropicales, bosques nubosos, cabeceras de cuencas hídricas. Además, este tipo de explotación implica la utilización de sustancias químicas y la generación de desechos potencialmente contaminantes; así como el uso desmesurado de agua y energía, lo que agota elementos de la naturaleza no renovables o que requieren largos periodos para su renovación (Tetreault, 2014).

Igualmente, el neoextractivismo tiene serias implicaciones socioculturales asociadas a la fragmentación, superposición y pérdida del control sobre los territorios de comunidades rurales (Bebbington, 2007), efectos nocivos sobre la salud, transformaciones en las formas de vida y las economías locales, debilitamiento de la soberanía y la seguridad alimentaria, destrucción de redes sociales y formas organizativas, agravamiento de la pobreza y la inequidad social y aumento de la violencia, la criminalidad y la represión (Svampa, 2011).

En términos de las relaciones económicas, esta práctica acentúa el proceso de reprimarización de las economías latinoamericanas (Cypher, 2009). De acuerdo con el PNUMA (2013), la extracción de las cuatro categorías principales de materias primas en América Latina tuvo un fuerte crecimiento en el período de 1970 a 2008: la extracción de biomasa aumentó al $2 \%$ anual, los combustibles fósiles al 2,5\% anual, los minerales metálicos y minerales industriales al 5,5\% anual y los minerales de construcción al 3,5\% anual (Ver gráfica 2).

Al respecto, Joan Martínez-Alier y Mariana Walter (2016) plantean que:

el auge de la extracción de materias primas en Latinoamérica ha sido particularmente significativo para los minerales metalíferos. Mientras en 1970 los minerales metalíferos e industriales suponían el 10\% del total de los flujos materiales de Latinoamérica, en 2009 alcanzaron el $25 \%$. De hecho, 


\section{Gráfica 2. Extracción de las cuatro categorías principales de materias primas en América Latina (1970 a 2008)}

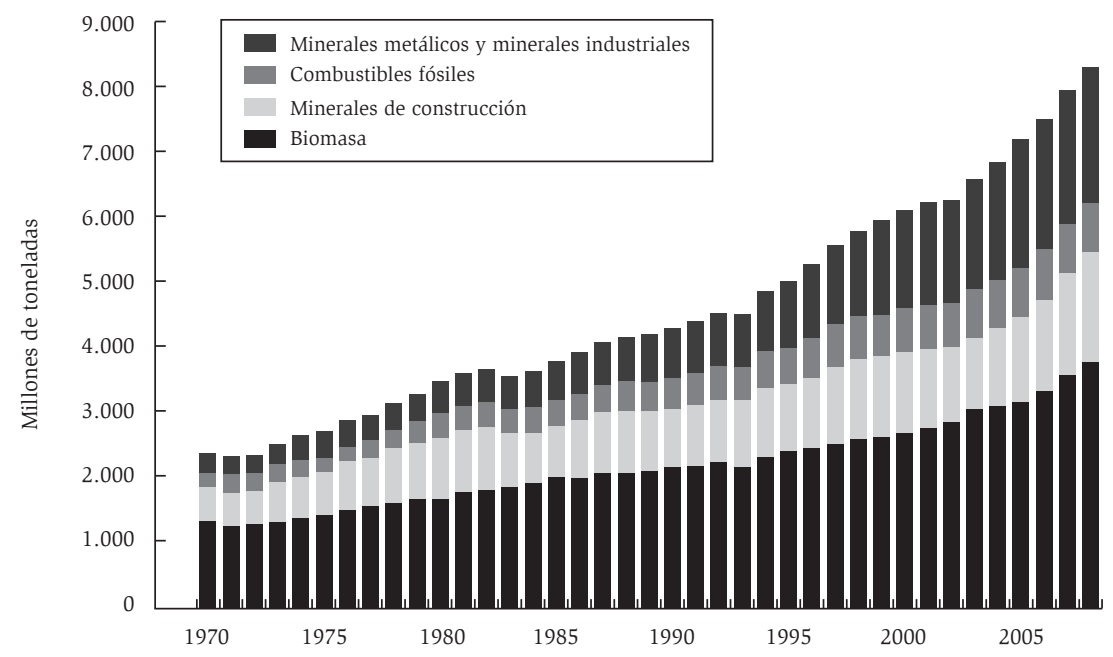

Fuente: PNUMA (2013)

en 2009 los minerales metalíferos e industriales fueron, después de la biomasa, el segundo material más extraído y, en parte, exportado de la región, alcanzando 2100 millones de toneladas de minerales [...] En 2012, Latinoamérica proveyó el $45 \%$ de la producción mundial de cobre, así como el $50 \%$ de la plata, el $21 \%$ del zinc y el $20 \%$ del oro [...] atrayendo un tercio de las inversiones mundiales en minería metalífera (210 mil millones de dólares) (p.90).

En el ámbito macroeconómico, las grandes exportaciones de materias primas que traen consigo impactos ecológicos y socioculturales no alcanzan a financiar las importaciones. Países como Colombia, Brasil, Perú, Venezuela y Ecuador están entrando en déficits comerciales y nuevos procesos de endeudamiento que se buscan compensar a través de la inversión extranjera directa (Martínez-Alier y Walter, 2016) (ver gráfica 3). 
Gráfica 3. Déficit comercial físico de las cuatro categorías principales de materias primas en América Latina (1970 a 2008)

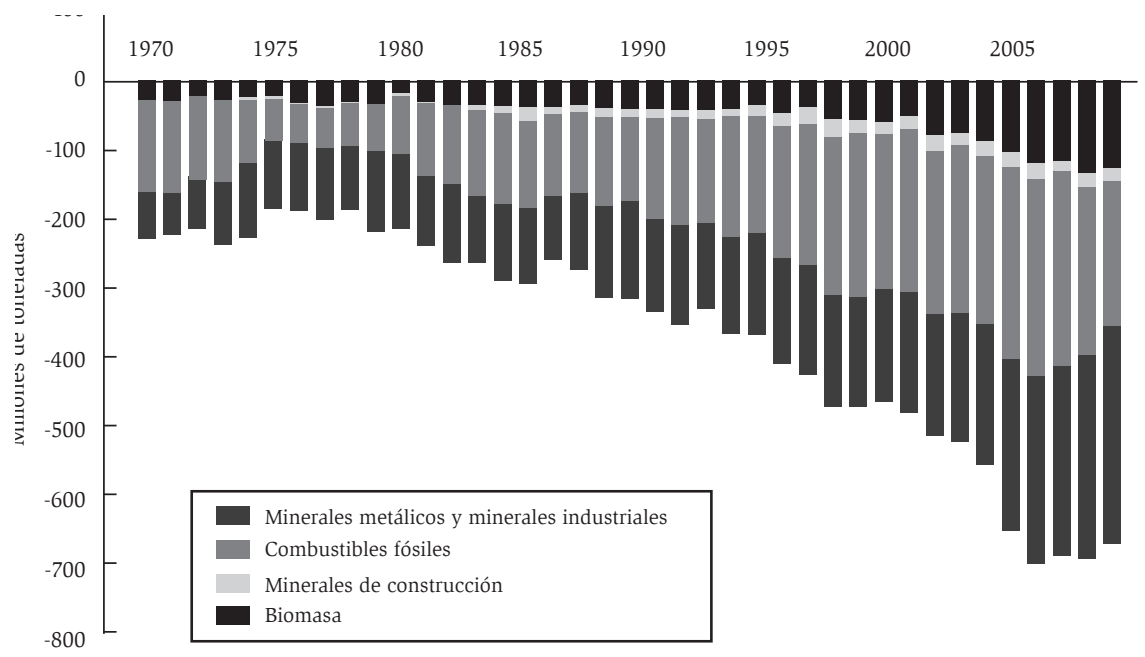

Fuente: PNUMA, 2013

El neoextractivismo refleja términos de intercambio estructuralmente desfavorables porque se basa en economías de enclave que no generan "encadenamientos positivos hacia adelante, hacia atrás, de demanda final y horizontales con el resto de la economía” (Cypher, 2009, p.145). Dichas economías son muy dependientes de inversiones extranjeras y están supeditadas a cadenas de comercialización global con bajas o inexistentes cargas tributarias, así como bajas tasas de generación de empleo. El intercambio económico en general ocurre para el beneficio de las corporaciones multinacionales a costa de las comunidades locales (Martínez-Alier y Walter, 2016).

Sin embargo, durante los últimos años las comunidades locales afectadas por el neoextractivismo han cuestionado la legitimidad de este modelo de desarrollo y el funcionamiento aparentemente normal y natural de sus efectos sobre la sociedad y la naturaleza (Escobar, Álvarez y Dagnino, 2001). Estas comunidades privilegian el valor de uso por 
sobre el valor cambio, pues la reproducción social de la vida no está puesta en función de las ganancias, sino de la vida misma (Composto y Navarro, 2014).

Con el apoyo de diversos sectores sociales, las comunidades afectadas han conformado un movimiento social heterogéneo que pone en el centro de sus discursos y estrategias la justicia ambiental, desde intereses materiales y simbólicos (ver gráficas 4 y 5). De acuerdo con Harvey (2004), estos son movimientos insurgentes que luchan contra la acumulación por desposesión y la reproducción ampliada del capital.

\section{Gráfica 4. Agentes sociales movilizados por la justicia ambiental}

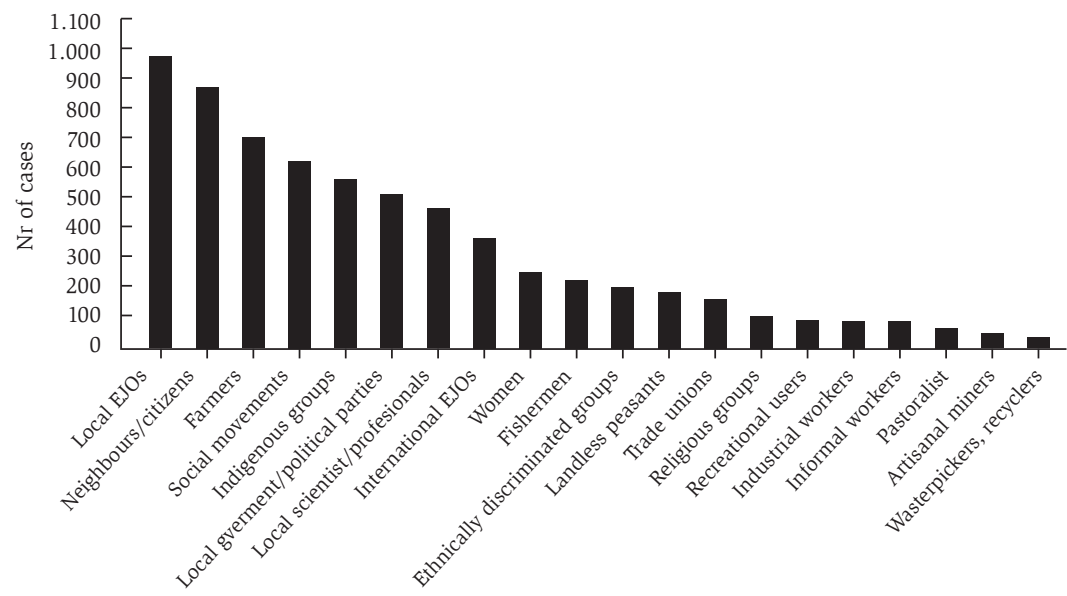

Fuente: Martínez-Alier, Temper, Del Bene y Scheidel, 2016

La justicia ambiental ha permitido poner en primer plano las luchas por el territorio como un patrimonio y un derecho. Han surgido nuevas organizaciones locales conformadas por diversos sectores: comunidades afectadas, trabajadores vinculados a las empresas extractivas, pobladores urbanos, activistas, académicos, investigadores, aun representantes de instituciones públicas. 


\section{Gráfico 5. Formas de movilización por la justicia ambiental}

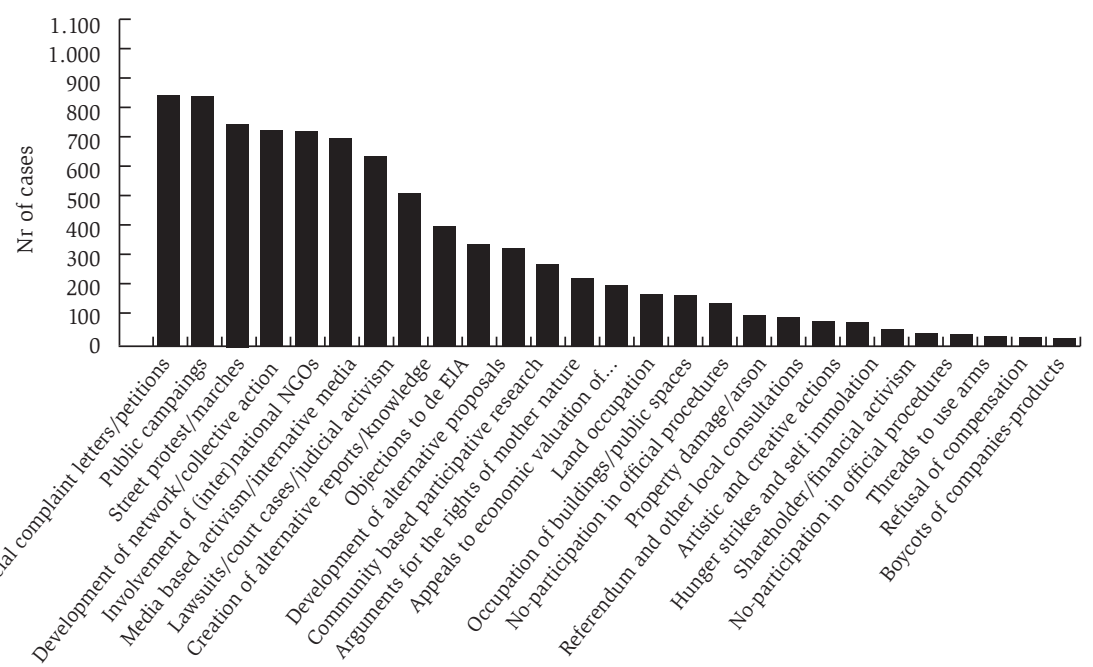

Fuente: Martínez-Alier, Temper, Del Bene y Scheidel, 2016

También se ha logrado la articulación de estos sectores sociales con organizaciones internacionales como Vía Campesina, Amigos de la Tierra, el Tribunal Permanente de los Pueblos, el Movimiento Mundial por los Bosques - WRM-, la Alianza de Organizaciones Católicas para el Desarrollo - Cidse-, el Observatorio de Conflictos Mineros de América Latina - Ocmal- , International Rivers, la Red Latinoamericana contra Represas, entre otras. De esta manera, se alcanzan mayores respaldos a través de la construcción de redes de solidaridad entre territorios afectados por el neoextractivismo.

Además de lo anterior, se están generando propuestas alternativas locales como el manejo forestal comunitario y el ecoturismo en Capulálpam en la Sierra Juárez del Estado de Oaxaca (Tetreault, 2014), o como el Proceso de Comunidades Negras - $\mathrm{PCN}$ - en el Pacífico colombiano, centrado en la apropiación y el control social del territorio como base para la seguridad alimentaria, la autosubsistencia y la autonomía (Escobar, 2008). 
Están surgiendo también nuevas formas de movilización y participación ciudadana, así como acciones legales ante tribunales nacionales e internacionales para exigir el derecho de las comunidades a las consultas previas y populares con el propósito de detener los megaproyectos extractivos o minimizar sus impactos.

Conviene mencionar que las alternativas al desarrollo apelan a procesos productivos "orientados a asegurar las necesidades de las personas y la conservación de la naturaleza, y no las tasas de ganancia o rentabilidad de los emprendimientos extractivos" (Gudynas, 2011b, p.395), como sucede por ejemplo con la minería de oro $^{1}$. No buscan prohibir las actividades extractivas per se, sino redimensionarlas para que permanezcan "aquellas que son genuinamente necesarias, que cumplan condiciones sociales y ambientales, y estén directamente vinculadas a cadenas económicas nacionales y regionales" (Gudynas, 2011b, p.392).A propósito de lo anterior, Esteva y Prakash (1998), anuncian que:

lo que se necesita [...] es que cada pueblo, con referencia a sus propios valores y sobre la base de la acción autónoma y las organizaciones de base, teja sobre sus propios tejidos culturales y construya así su propio futuro [...] Esta construcción social de la realidad [...] tiene un nuevo centro de referencia: una épica emergente de las bases sobre la lucha localizada, el drama de las formas cotidianas de resistencia y una amplia colección de iniciativas y luchas culturalmente diversas (Esteva y Prakash, 1998, p.3; c.p. Veltmeyer, 2003, p.4)

1 Un $49 \%$ de la demanda física de oro en la actualidad se destina a joyería, un $41 \%$ en forma de inversión en barras y monedas, y un $10 \%$ en industria. Hasta 2010 se habían extraído de la tierra 168 mil toneladas de oro (5 400 millones de onzas troy). Un $50 \%$, 84 100, está ahora en joyería y objetos de lujo. Un 15\%, 20 200, en aplicaciones tecnológicas e industria. En inversión privada, un 18\%, 31400 toneladas. Un $17 \%$, 29000 toneladas, en manos de los gobiernos de los países y un porcentaje muy exiguo sin identificar (Suárez Montoya, 2013). 


\section{Problemática del neoextractivismo en Colombia}

Colombia manifiesta las dinámicas actuales del neoextractivismo como país periférico y dependiente. Así, este modelo de acumulación fue declarado como la principal locomotora de desarrollo ${ }^{2}$ en la nación con el conflicto social y armado más largo del continente. Opera a través de megaproyectos orientados a la explotación de minerales (oro, carbón, petróleo, ferroníquel, plata, cobre, coltan, mulidleno, uranio, materiales de construcción, hierro y acero) y biomasa (caña, palma, pinos, eucaliptos y madera) (Pérez-Rincón, Sánchez Torres y Zúñiga de Cardoso, 2014), asociados con sistemas de infraestructura en materia de transporte y energía, en el marco de los planes de la Iniciativa para la Integración de la Infraestructura Regional Suramericana - IIRSA- y Mesoamérica.

En particular, los planes nacionales y las políticas sectoriales de las dos últimas décadas han establecido las condiciones legales, financieras e institucionales necesarias para promover la inversión extranjera directa. En este esquema, las empresas privadas y extranjeras se ven como los únicos agentes con alto potencial de impulsar el crecimiento económico del país. En este orden de ideas, las inversiones de estos gigantes se atraen mediante la ausencia de impuestos, garantías tributarias y la posibilidad de explotar mano de obra barata y de externalizar impactos ecológicos, culturales y sociales (Arias Hurtado, 2014).

En concordancia con lo anterior, resulta ilustrativo que en Colombia la inversión extranjera directa orientada a megaproyectos mineros y de hidrocarburos aumentara del $21 \%$ al $85 \%$ entre los años 2000 y 2010 (Toro, 2012). Por su parte, la inversión extranjera en proyectos de agro-

2 En el Plan Nacional de Desarrollo Prosperidad para Todos (2010-2014), el sector minero-energético y el agropecuario se establecieron como locomotoras de desarrollo. Este propósito es retomado en el actual plan nacional de desarrollo Todos por un Nuevo País. Paz, Equidad y Educación (2014-2018), en el denominado eje transversal de transformación del campo y crecimiento verde que busca consolidar la agroindustria y la gran minería. 
industria, agricultura, silvicultura y pesca creció $241 \%$ entre los años 2010 a 2014 (Delgado Gómez, 2015).

La actuación del Estado, producido y reproducido históricamente por las lógicas del capital, ha guardado una coherencia profunda respecto a las estrategias de modernización y desarrollo impulsadas por las corporaciones transnacionales y los nuevos centros imperiales de donde proceden, como es el caso de Canadá, en alianza con los grandes terratenientes colombianos y el sector privado nacional.

Según la Contraloría General de la República, desde 1997 el Gobierno canadiense intervino en la formulación del Código de Minas colombiano, a través de un convenio entre el Ministerio de Minas y Energía de Colombia, la Canadian International Development Agency —CIDA- y el Canadian Energy Research Institute - CERI-, en el que las agencias citadas invirtieron recursos para fortalecer las instituciones mineras del país sudamericano, al tiempo que el Gobierno colombiano se comprometía a garantizar las condiciones para la inversión de las compañías mineras con sede en ese país y de propiedad canadiense (Fierro Morales, 2012). De esta manera, para el año 2012 en Colombia operaban cuarenta compañías canadienses con ochenta y seis proyectos mineros (Grupo de Trabajo sobre Minería y Derechos Humanos en América Latina, 2014).

El neoextractivismo ha implicado no solo enormes impactos sociales y naturales, sino también impactos económicos, políticos y culturales, debido a que el control por el territorio y sus riquezas naturales ha estado en el corazón del conflicto y la guerra más larga del continente. Sumado a lo anterior, hay que hacer evidente lo nocivo que resulta que dentro de los Acuerdos de Paz no haya cuestionamientos sustantivos a este modelo económico.

De los ochenta y ocho conflictos socioambientales identificados en Colombia por el Atlas de Justicia Ambiental, el 54\% involucran cor- 
poraciones transnacionales. Del total de los casos, treinta y cuatro corresponden a conflictos por minería - se destaca la minería de oro con veintisiete casos-, veintidós a conflictos por combustibles fósiles —se destaca el carbón con doce casos y el petróleo con nueve-, trece a conflictos por biomasa - se destaca el cultivo de palma con seis casos-, diez a conflictos por generación eléctrica y nueve por infraestructura (Pérez-Rincón, 2015) (ver gráfica 6).

\section{Gráfica 6. Conflictos socioambientales por el neoextractivismo en Colombia}

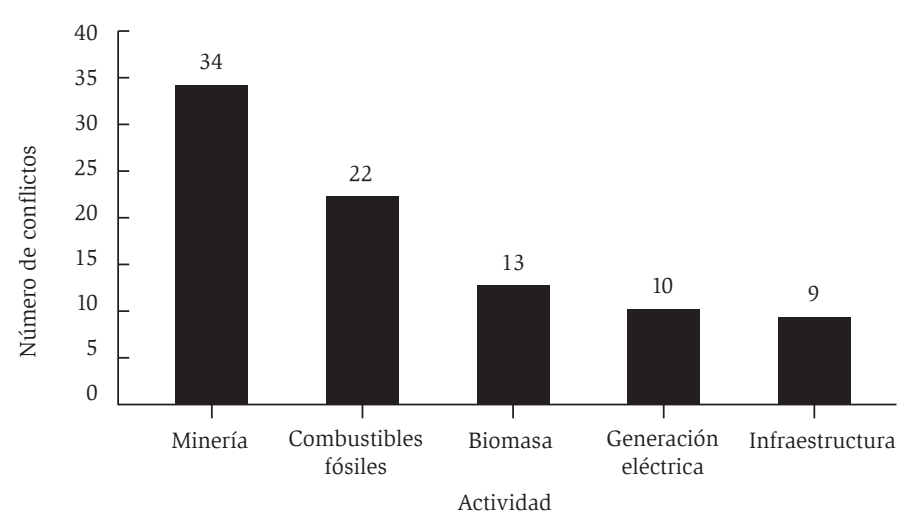

Fuente: Elaboración propia con datos de Pérez-Rincón, 2015

Aunque los conflictos socioambientales generados por el neoextractivismo están presentes en todas las regiones de Colombia, se ubican principalmente en las zonas más pobladas (Andina y Caribe), así como en zonas de conservación y territorios ancestrales. Cerca de 7,9 millones de personas han sido afectadas, particularmente las comunidades campesinas, indígenas y afrodescendientes (Pérez-Rincón, Sánchez T. y Zúñiga de Cardoso, 2014).

En términos de las relaciones económicas el escenario no es menos favorable. Se acentúa cada vez más el carácter dependiente y el proceso 
de reprimarización. En los últimos años, el valor de las exportaciones es apenas la cuarta parte del costo de las importaciones (Samaniego, Vallejo y Martínez-Alier, 2014, p.25). Como lo detallan Joan Martínez Alier y Mariana Walter (2016):

Las importantes exportaciones físicas de Colombia (que conllevan grandes pasivos socio-ambientales impagos) ahora no pueden pagar las importaciones [...] En 2011 Colombia exportó cerca de 120 millones de toneladas e importó cerca de 30 millones de toneladas, dejando un déficit comercial físico de más de 90 millones de toneladas. Esto es para un país de más de 45 millones de habitantes [...] Crecientes exportaciones en toneladas (de diferentes commodities) no logran mejorar los balances comerciales monetarios debido a los términos de intercambio negativos (p.82).

Adicionalmente, más de la mitad de los megaproyectos extractivos en el país se encuentran en manos de inversión extranjera directa asociada con altos valores de transferencias de rentas. En el 2013, se transfirieron por rentas 7,8 puntos porcentuales más que en el año 2000:

De cada 100 dólares exportados, ahora deben pagar en calidad de rentas alrededor de 22 dólares. Es decir, si la IED está concentrada en bienes primarios no renovables, además de provocar un déficit creciente del balance comercial físico y el agotamiento o degradación de recursos naturales, se debilita la posición en la balanza de pagos. No se puede despreciar que una cuarta parte de las exportaciones esté comprometida con el pago de rentas al exterior (Samaniego et al., 2014, p.25).

Es así como los impuestos sobre la producción de commodities son simbólicos o por completo inexistentes (Cypher, 2009). En tal sentido:

Colombia es actualmente el destino preferido de los inversionistas extranjeros (seguido por Brasil y Chile y luego por México); aplicó una política de 'flexibilidad' para fijar las tasas por regalías ( $1 \%$ en el caso de la minería de oro) y aún no ha decidido cómo o cuándo se aplicarán (Veltmeyer, 2013, p.29). 
En consecuencia, en nuestro país el neoextractivismo afecta a los territorios y a la identidad cultural de comunidades indígenas, afrodescendientes y campesinas. Además, representa en muchos casos la pérdida del control sobre el uso de la tierra, la soberanía alimentaria y las redes de comercio locales, y afecta ecosistemas estratégicos como páramos, selvas, bosques andinos, ríos y humedales (Defensoría del Pueblo, 2010). Sin contar con que también causa desplazamientos forzados, amenazas y desapariciones de líderes, así como actos sistemáticos y generalizados tendientes a generar procesos de terror y ruptura del tejido social (Ramírez, 2007). Igualmente, es responsable de la intensificación de los procesos de militarización articulados con acciones paramilitares (Idárraga Franco, Muñoz Casallas y Vélez Galeano, 2010).

\section{Acciones frente al neoextractivismo en Colombia}

Si sesenta años de desarrollo no han producido los resultados esperados, ¿no es ya hora de repensar radicalmente esta forma de concebir la realidad social? Por eso, aunque en estos momentos el neoextractivismo parece empecinado en seguir por este mismo camino, aún es posible imaginar y adelantar proyectos alternativos. (Modificado de Escobar y Pedrosa, 1996)

Para el periodo 2001-2011, se registraron doscientas setenta y cuatro acciones sociales colectivas contra del neoextractivismo en Colombia: marchas, reclamos, paros cívicos, bloqueos de vías y huelgas de hambre. Dichas acciones tuvieron un ascenso desde el año 2005 y un crecimiento sostenido a partir del año 2008 (Cinep, 2012) (ver gráfica 7).

En estas acciones participaron sectores diversos: campesinos, indígenas y afrocolombianos, mineros tradicionales (trabajadores independientes), trabajadores vinculados a las empresas extractivas (asalariados), pobladores urbanos, activistas, académicos e investigadores (Cinep, 2012) (ver gráfica 8). 


\section{Gráfica 7. Acciones sociales contra el neoextractivismo en Colombia (2001-2011)}

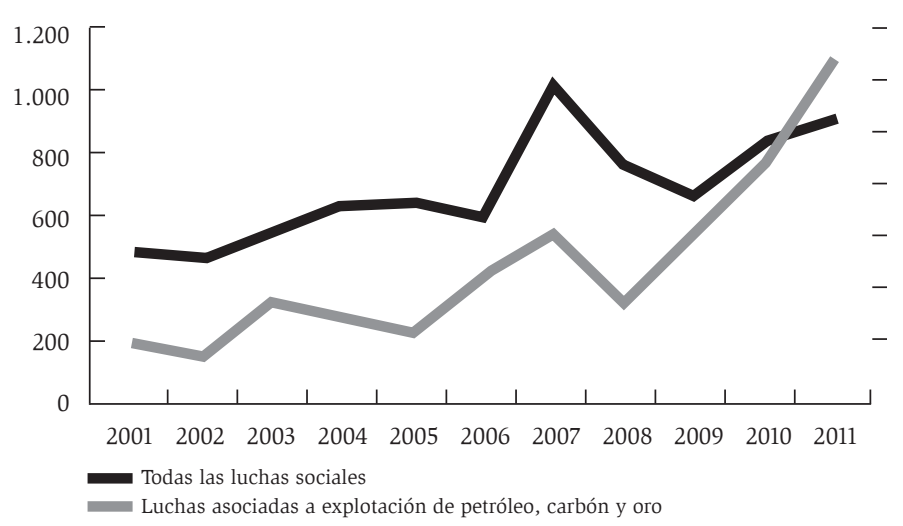

Fuente: Cinep, 2012 (Modificado de Escobar y Pedrosa, 1996)

\section{Gráfica 8. Participación de diferentes sectores (2001-2011)}

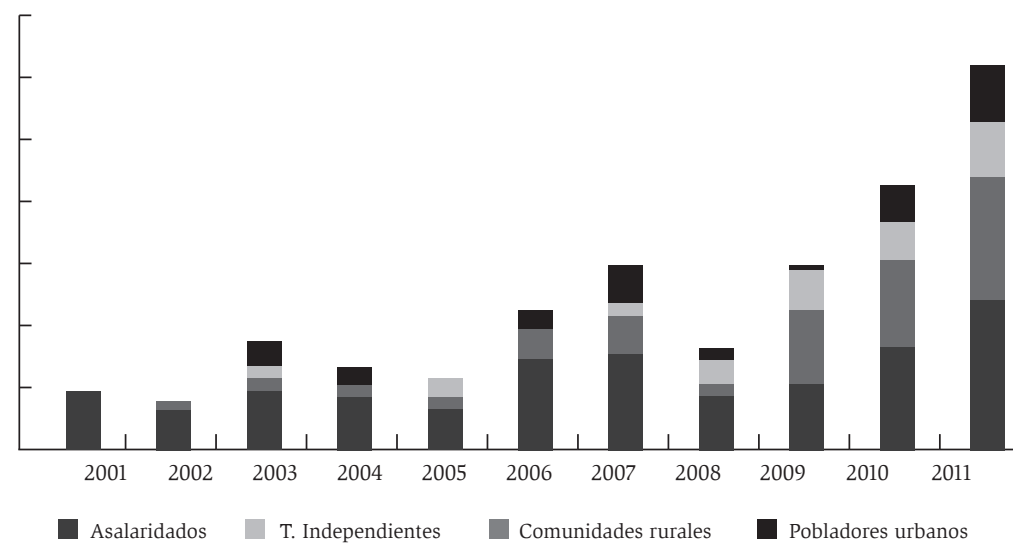

Fuente: Cinep, 2012 


\section{Gráfica 9. Motivo de las acciones sociales (2001-2011)}

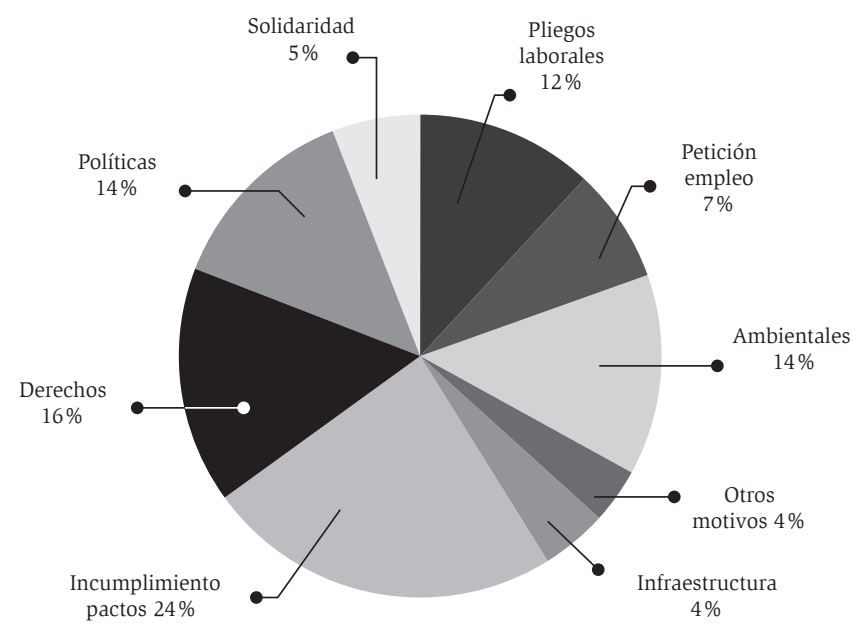

Fuente: Cinep, 2012

Entre los principales motivos de las acciones se encuentran las violaciones a los derechos de comunidades indígenas y afrodescendientes, la protección del medio ambiente, el incumplimiento de acuerdos entre las empresas y sus empleados, así como la petición de pliegos laborales (Cinep, 2012) (ver gráfica 9).

Se ha logrado la articulación de los movimientos sociales en los ámbitos local y nacional, con movimientos internacionales de justicia ambiental como el Tribunal Permanente de los Pueblos, el Movimiento Mundial por los Bosques — WRM-, la Alianza de Organizaciones Católicas para el Desarrollo —Cidse-, el Observatorio de Conflictos Mineros de América Latina —Ocmal—, Colombia Support Network — CSN—, entre otras organizaciones. De esta manera, las luchas en el ámbito local alcanzan mayores respaldos globales.

En lo que respecta a lo jurídico, se han interpuesto derechos de petición, acciones de tutela, acciones de grupo, acciones de reparación directa, denuncias penales y presentación de casos ante tribunales in- 
ternacionales, como el Tribunal Permanente de los Pueblos — TPP- y la Comisión Interamericana, que incluyen el aporte de pruebas sobre la violación de derechos humanos y la destrucción de los territorios (Arias Hurtado, 2016).

Como casos emblemáticos se encuentran las acciones legales por medio de las cuales algunas comunidades han detenido los megaproyectos extractivos en sus territorios:

- En el 2010, mediante una acción de tutela, tres resguardos indígenas y dos territorios colectivos de afrodescendientes del municipio de Carmen de Darién (Chocó) lograron que la Corte Constitucional suspendiera el megaproyecto minero Mandé Norte de la Muriel Mining Corporation y Rio Tinto.

- En el 2013, mediante la primera consulta popular sobre proyectos extractivos en Colombia, el municipio de Piedras (Tolima) rechazó el megaproyecto minero de la Anglo Gold Ashanti.

- En el 2014, mediante una consulta popular, el municipio de Tauramena (Casanare) rechazó el megaproyecto petrolero de Ecopetrol.

- En marzo de 2017, mediante una consulta popular, el municipio de Cajamarca (Tolima) rechazó el megaproyecto minero La Colosa de la Anglo Gold Ashanti.

- En febrero de 2017, mediante una acción de tutela, los mineros tradicionales del municipio de Marmato (Caldas) lograron que la Corte Constitucional aprobara la realización de una consulta previa frente al megaproyecto minero de la Gran Colombia Gold Corp.

- En julio de 2017, mediante consulta popular, los habitantes de Pijao (Quindío) rechazaron la explotación minera en su territorio y los de Arbeláez (Cundinamarca) la explotación de hidrocarburos.

Como resultado de la presión social, algunas instituciones parecen estar obrando como la "mano izquierda del Estado” (Bourdieu, 2014), al tomar el papel de ser partidarias de la defensa de los derechos socia- 
les. Tal es el caso de la Controlaría General de la República y la Corte Constitucional. Estas instituciones han legitimado sus actuaciones en las contribuciones realizadas por académicos e investigadores de esta problemática, lo que genera una alianza con las clases tendiente a reconstruir el sentido público del Estado, de manera antagónica frente a las clases dominantes.

El máximo órgano de control fiscal, bajo la dirección de Sandra Morelli, denunció los impactos lesivos del neoextractivismo sobre los derechos humanos, el ambiente y la economía, lo cual fue documentado por un reconocido grupo de académicos y asesores bajo la dirección del investigador social Luis Jorge Garay.

Por su parte, la Corte ha exigido al Estado la protección constitucional de los ecosistemas de páramo de actividades extractivas, debido a su alta fragilidad (Sentencia C-035/16), así como la protección constitucional de los derechos fundamentales a la consulta previa, al territorio y a la diversidad étnica y cultural de las comunidades indígenas y afrodescendientes que habitan los territorios que se pretendan declarar y delimitar como áreas estratégicas mineras (Sentencia T-766-2015) (Iespa, 2016).

Es así como las comunidades afectadas, con el apoyo de diversos sectores del ámbito nacional e internacional, han constituido un movimiento social que se articula en torno a la justicia ambiental y la defensa del territorio: una propuesta local unida a la globalización de las resistencias que cuestionan las lógicas del neoextractivismo.

\section{Marmato y la defensa del territorio}

En este contexto resulta representativo el caso de Marmato, el cuarto pueblo más antiguo de Colombia ubicado al centro-occidente del país, en el departamento de Caldas. Su principal patrimonio natural lo constituye el cerro El Burro, donde se localiza el oro que lo ha posicionado como uno de los territorios con mayor riqueza minera del continente, 
así como su centro histórico declarado en 1982 monumento histórico nacional (Arias Hurtado, 2014).

La historia cultural, social, económica y política de Marmato se encuentra asociada directamente con la práctica de la minería de oro que, inicialmente, era llevada a cabo por las comunidades aborígenes durante la época prehispánica. Durante el siglo XVI, este municipio se constituyó como un real de minas perteneciente a la jurisdicción de Popayán; a finales del siglo XVI y hasta el siglo XVIII fue parte de la Real Compañía de Minas de la Provincia de Popayán. Finalmente, entre 1825 y 1930 el cerro minero fue entregado en empréstito a compañías inglesas para consolidar la independencia de la Gran Colombia (Arias Hurtado, 2013).

A partir de la década de los años treinta del siglo Xx se inició la configuración de la minería tradicional en el municipio ${ }^{3}$. Esta era realizada por comunidades indígenas, afrodescendientes y mestizas ${ }^{4}$ y estaba basada en la valoración de la autonomía y la solidaridad. Entre 1940 y 1980 el Ministerio de Minas promovió la empresa individual y las formas asociativas de pequeños mineros independientes, quienes constituyeron agrupaciones de hecho y luego se transformaron en sociedades de

3 Entre 1926 y 1931 el Estado recupera el control de las minas de Marmato, ya que a inicios del siglo xx fueron entregadas al General Vásquez Cobo, quien las arrienda a la compañía C.W. Sindycate Limited que, a su vez, traspasó el contrato a la compañía inglesa Colombian Mining-Exploration Co. Es así como en la década de los años treinta del siglo xx las minas fueron cedidas en arrendamiento a diferentes empresarios nacionales, quienes al no contar con recursos para explotar el preciado metal de manera "razonable" apelaron a subarrendarlas a pequeños mineros independiente locales, que se constituyeron como mineros tradicionales (Arias Hurtado, 2014).

4 De acuerdo con las proyecciones del Dane (2005), para el año 2011 la población de Marmato estaba considerada en 8848 habitantes, de los cuales el 56,5\% corresponde a población afrodescendiente quienes tienen sus orígenes en la época de la esclavitud; el 16,7\% a población indígena proveniente del Chocó durante la época de la colonización por la Provincia de Popayán y que actualmente integran la Parcialidad Indígena de Cartama; y el $28,6 \%$ restante se reconocen como mestizos (Arias Hurtado, 2016). 


\section{Imagen 1. División territorial y cultural de las minas de Marmato de acuerdo con la Ley 66 de 1946}

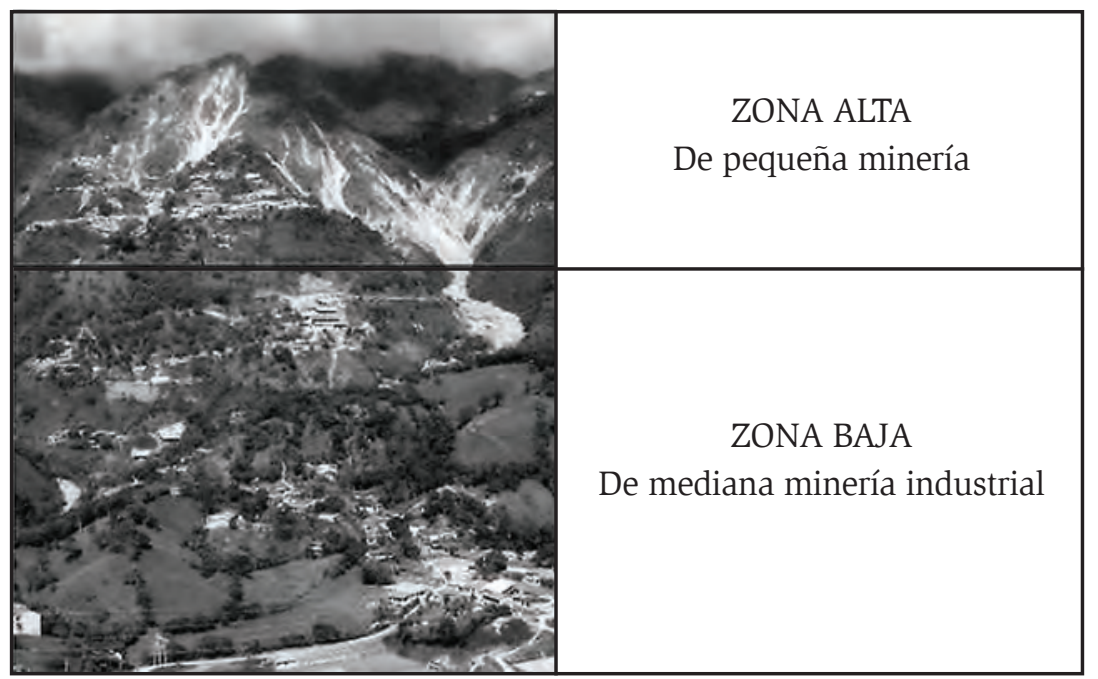

Fuente: Modificado de Medoro Resources, 2011

derecho, suscribiendo contratos de explotación de las minas de la parte alta de Marmato de acuerdo con la Ley 66 de 1946, normatividad que promovió un modelo de explotación a través de la división territorial y cultural (ver ilustración 1).

La zona alta donde se localiza el cerro El Burro y en donde se encuentra el centro histórico se destinó para la pequeña minería; y la zona baja, en donde se encuentra la vereda El Llano, actualmente "zona de expansión urbana”, se reservó para la mediana minería (Arias Hurtado, 2014).

A finales de la década de los años ochenta, se expidió el Decreto 2655 de 1988, bajo el cual Ecominas impulsó la firma de contratos para la pequeña minería en la zona alta de Marmato, cuya duración coincidía con la vida útil del yacimiento. Posteriormente, de acuerdo con el pro- 
grama de legalización establecido por la Ley 141 de 1994, Minerales de Colombia - Mineralco S.A. - celebró alrededor de ciento veintidós contratos para la pequeña minería en la zona alta que permitieron a los pequeños mineros legalizar la minería de hecho (Arias Hurtado, 2016).

No obstante, desde la década de los años noventa el oro presente en Marmato se configura como un "recurso" de interés para el desarrollo de un megaproyecto de minería a cielo abierto, liderado actualmente por la transnacional Gran Colombia Gold Corp. ${ }^{5}$, que se compone de tres áreas: zona alta, zona baja y zona Echandía que colinda con la zona alta (Gran Colombia Gold, 2012). Este proyecto requiere el traslado del centro histórico - ubicado en la zona alta o cerro El Burro-, lo que implica el desplazamiento de la comunidad de su territorio:

El proyecto minero afectará tanto a la zona alta de Marmato como a la vereda El Llano y otras veredas del municipio, como San Juan, Boquerón, Echandía y Cabras que pueden requerir reinstalación completa [...] Habrá necesidad de desarrollar un nuevo municipio en otro lugar. Esto requeriría

5 Entre 1995 a 1997 la compañía Gran Colombia Resource Inc. llevó a cabo exploraciones en la zona de Echandía, que colinda con la zona alta donde se encuentra el centro histórico de Marmato.

Entre 1996 a 2000 la compañía canadiense Conquistador Mines Ltd., a través de su filial colombiana Corona Goldfields S.A., adquirió el 13,15\% de la zona baja propiedad de Mineros Nacionales y compró varias minas de la zona alta donde se ubica el centro histórico de Marmato.

Entre 2005 a 2009 la compañía canadiense Colombia Goldfields Limited, a través de su filial en Colombia, la Empresa Minera de Caldas, adquirió varias minas de la zona alta.

En el 2010, la compañía canadiense Medoro Resource Ltd. adquirió las minas de Mineros Nacionales ubicadas en la parte baja.

En el 2011, la compañía canadiense Medoro Resource Ltd. se fusionó con la transnacional panameña Gran Colombia Gold, bajo el nombre de Gran Colombia Gold Corp., para adquirir en concesión la zona alta, la zona baja y la zona Echandía que colinda con la zona alta (Arias Hurtado, 2014). 
una importante colaboración entre la población y el gobierno colombiano (Gran Colombia Gold, 2012).

Es importante advertir que para el año 2012, según el máximo órgano de control fiscal del Estado:

No ha sido formalmente presentado un proyecto de gran minería en Marmato con las características habituales de un proyecto minero [...] por las empresas del grupo empresarial de la canadiense Gran Colombia Gold Corporation [...] Tal es la situación, que ni la Gobernación de Caldas, ni la Agencia Nacional Minera, ni el Ministerio de Minas pueden afirmar tener conocimiento de dicho proyecto. Pese a esto, el megaproyecto para oro en la zona de Marmato fue presentado en el sitio web de la empresa Gran Colombia Gold, lo cual no se trata de manera alguna de una propuesta presentada de manera oficial aunque haya sido objeto de noticia en la prensa nacional o inclusive haya sido tema de discurso del exministro de minas Carlos Rodado [...] No obstante la situación anterior, el tema del megaproyecto aurífero resultaría ser un tema de especial interés para la Contraloría General de la República desde el momento en que este proyecto sea presentado oficialmente, puesto que su planteamiento y realización deben presentar las características propias de un proyecto sustentable. Preocupa de un proyecto de estas magnitudes y características las implicaciones ambientales y sociales. Indudablemente un proyecto que se plantee para ser realizado a cielo abierto [...] con la eliminación de un cerro y la generación de un pit de más de 800 metros de profundidad, con la remoción y reubicación de millones de toneladas de estériles, arroja serios problemas ambientales que deben ser evaluados [...] Además de todos estos detalles sobre lo acontecido en torno al tema de Marmato, interesantes de por sí, para la Contraloría General de la República resulta de interés el hecho de que el reasentamiento corresponda verdaderamente a una necesidad de la comunidad de Marmato o a una conveniencia de intereses empresariales [...] Esta situación por lo visto ha reunido un variado número de intereses y es probable que tenga implicaciones de orden fiscal (Contraloría General de la República, 2012). 
Es así como se ha desconocido el derecho a la consulta previa e informada de la comunidad de Marmato, integrada por población indígena, afrodescendiente y mestiza. De hecho, se ha despojado del mínimo vital y único sustento de vida a los mineros tradicionales y también se han vulnerado las prácticas históricas y culturales de los marmateños, junto con la libertad para ejercer el oficio de mineros tradicionales. Sumado a lo anterior, esta práctica ha promovido la apropiación del territorio por parte de una sola compañía, lo que agudiza de manera tajante la problemática estructural de Colombia: la concentración de la tierra (Arias Hurtado, Monsalve y Cubillos, 2016).

Tampoco ha existido un debido proceso frente a la "legalización” de los mineros tradicionales de Marmato, de acuerdo con el Código de Minas del año 2001. La Unidad de Delegación Minera de Caldas era la responsable de desarrollar la "legalización” en el municipio hasta el año 2005, por medio del otorgamiento de títulos a los mineros tradicionales. Este proceso inició en el 2004; sin embargo, a la fecha, existen solicitudes sin respuesta. Además, el nuevo código ha desconocido el proceso de legalización de títulos desarrollado en 1994, así como el régimen especial en la división territorial y cultural promovida por la Ley 66 de 1946 que había regido la relación entre el Estado y los mineros tradicionales (Arias Hurtado, Monsalve y Cubillos, 2016).

La defensa del territorio dio origen a la Asociación de Mineros Tradicionales de Marmato y al Comité Cívico Prodefensa de Marmato. Estas organizaciones han logrado la articulación con movimientos sociales en el ámbito nacional e internacional ${ }^{6}$, al tiempo que han apelado a diversas formas de movilización y participación ciudadana.

6 Como Colombia Support Network, la Confederación Nacional de Mineros de Colombia, el partido político Polo Democrático Alternativo, el Centro de Estudios Mineros Colombia Punto Medio, la Red Colombiana Frente a la Gran Minería Transnacional y diferentes universidades del país, como la Universidad Tecnológica de Pereira. 
Como resultado de una acción de tutela para que se amparen los derechos fundamentales al debido proceso, la libertad para ejercer el oficio de mineros tradicionales, el mínimo vital, el derecho a no ser desplazados del territorio y a la participación, las organizaciones sociales de Marmato lograron que el pasado 28 de febrero de 2017 la Corte Constitucional aprobara la realización de una consulta previa frente al megaproyecto, mediante la Sentencia SU- 133/17:

La Corte Constitucional protegió el derecho de los habitantes y de los mineros tradicionales de Marmato a participar en la definición de los impactos de las cesiones de los derechos de explotación de la parte alta del cerro El Burro y el derecho de las comunidades indígenas y afrocolombianas del municipio a ser consultadas al respecto (Corte Constitucional, 2017, p.1).

Para tal efecto, fueron convocadas varias universidades del país, entre las que se encuentran "la Universidad Tecnológica de Pereira, que participó en el debate en la Corte por el amparo de los derechos de los mineros artesanales de esta región” (Laverde y Medellín, 2017, p. 4), a través de la Línea de Investigación Estudios Socioculturales y Problemática Ambiental -Iespa- ${ }^{7}$.

Es así como la Asociación de Mineros Tradicionales de Marmato y el Comité Cívico Prodefensa de Marmato han constituido un movimiento social como una propuesta local a la globalización de las resistencias que cuestionan las lógicas del neoextractivismo. La reciente sentencia de la Corte Constitucional es una conquista de este movimiento que se articula en torno a la justicia ambiental y la defensa del territorio desde intereses materiales y simbólicos.

7 En marzo del año 2016, la línea de investigación Estudios Socioculturales y Problemática Ambiental, adscrita al grupo de investigación Gestión en Cultura y Educación Ambiental de la Facultad de Ciencias Ambientales de la Universidad Tecnológica de Pereira, elaboró el concepto solicitado por la Corte Constitucional frente a la acción de tutela presentada por cuatro mineros tradicionales de Marmato. El concepto presentado, relacionado con el contexto histórico y cultural, los efectos económicos y sociales, así como el marco constitucional y legal, se sustentó en las investigaciones y publicaciones de la línea sobre el municipio de Marmato (Arias, 2013a, 2013b, 2014, 2016; Iespa, 2016a, 2016b) Ver: www.iespautp.tk 


\section{Conclusiones}

El argumento principal que intentó orientar esta reflexión sostiene que América Latina, en sus diferentes niveles territoriales (regional, nacional y local), ha sido insertada en la dinámica de acumulación capitalista a través del neoextractivismo y, en este marco, se están librando luchas de clases que buscan conservar o subvertir la lógica de este modelo.

En la nueva geopolítica del capital en la región, el neoextractivismo como modelo de acumulación basado en el control de los territorios para la explotación intensiva de la naturaleza ha cobrado una fuerza inusitada, al operar a través de megaproyectos que ponen en contacto lo local y lo transnacional, para desafiar a las soberanías estatales, independientemente del régimen político-económico.

Para tal efecto, se despliegan estrategias hegemónicas que profundizan el proyecto de colonialidad y dependencia histórica, así como el modelo neoliberal. Además, promueven la recolonización político-económica para la proyección de los intereses de los países hegemónicos en la región (Estados Unidos y Canadá, principalmente), la reprimarización de las economías y el debilitamiento de la regulación para que la inversión extranjera acceda a fuerza de trabajo y "recursos" estratégicos baratos.

Así, el neoextractivismo se configura actualmente como una de las formas de transferencia sistemática de plusvalor en la división internacional del trabajo y la acumulación incesante. Este modelo económico presenta innovaciones recientes en las nuevas lógicas de acumulación extensiva, por ejemplo, la conversión del patrimonio natural en commodities. Igualmente, el neoextractivismo configura un nuevo escenario de crisis ambiental que implica no solo la contradicción capital-trabajo, sino también la contradicción capital-naturaleza. En ese sentido, la sustracción de ganancias extraordinarias bajo la forma de renta del suelo mediante la instauración de economías de enclave deriva en muchos casos en conflictos y guerras por el control del territorio y su patrimonio natural. 
Tanto en América Latina como en Colombia, con el avance del neoextractivismo han aumentado los conflictos socioambientales (ecológicos, económicos y político-culturales), así como el conflicto armado, la violencia y la represión por el control del territorio y sus riquezas naturales, pero al mismo tiempo se ha intensificado la necesidad de confrontar este modelo de desarrollo, no solo desde fundamentos económicos, sino también político-culturales que ubican en el centro de la disputa la cuestión del territorio.

Reflejo de esta situación es el caso de Marmato, ya que, desde lo local, sus organizaciones sociales, conformadas por las comunidades afectadas, despliegan estrategias contrahegemónicas para defender el territorio y se articulan con movimientos nacionales e internacionales con el fin de generar propuestas alternativas y gestar nuevas formas de movilización y participación ciudadana, así como acciones legales para detener los megaproyectos o minimizar sus impactos.

En consecuencia, el neoextractivismo del siglo XXI expresa un espacio de lucha de clases entre los agentes sociales de los países centrales y de la región que lo legitiman como modelo de desarrollo frente a los agentes sociales que desde el contexto local están confrontándolo.

En este contexto, la ecología política latinoamericana, como campo teórico-metodológico en construcción, es relevante para los estudios sobre el neoextractivismo, en cuanto propende por la comprensión de las relaciones de poder en torno a la apropiación social de naturaleza y los conflictos socioambientales generados por este modelo de acumulación, al tiempo que permite redimensionar y articular las luchas sociales en torno a la justicia ambiental.

Finalmente, consideramos necesario profundizar los análisis de los factores histórico-materiales y simbólico-culturales en torno a la problemática del neoextractivismo en el siglo XXI en los distintos niveles territoriales (regional, nacional y local). Además, es crucial realizar in- 
vestigaciones socialmente comprometidas - desde la perspectiva de y para los de abajo- que permitan evaluar los avances y logros, así como los límites y retrocesos que se dan en las luchas contrahegemónicas.

\section{Referencias}

Alimonda, Héctor. (Ed.). (2011). La naturaleza colonizada. Ecología política y minería en América Latina. Buenos Aires: CLAcso.

Arias Hurtado, Carolina (2013). Neo-extractivismo vs. desarrollo local: El caso del pueblo minero de Marmato (Caldas). Scientia Et Technica, 3, 589-598.

Arias Hurtado, Carolina (2014). Conflictos territoriales y patrimoniales en "el pesebre de oro de Colombia”. Luna Azul, (39), 207-233.

Arias Hurtado, Carolina (2016). ¿Neo-extractivismo o desarrollo local? Conflictos territoriales y culturales en el pueblo minero de Marmato (Colombia). En Línea de Investigación en Estudios Socioculturales y Problemática Ambiental -IESPA- (Ed.) Memorias académicas del Primer Encuentro "Investigaciones socioculturales en el marco de la problemática ambiental del territorio" (pp. 98-129). Pereira: Universidad Tecnológica de Pereira.

Arias Hurtado, Carolina; Monsalve, Olga y Cubillos, León (2016). Concepto presentado a la Corte Constitucional por parte de la Facultad de Ciencias Ambientales de la Universidad Tecnológica de Pereira frente al expediente T-4561330-Marmato (p. 52). Pereira: Corte Constitucional.

Bebbington, Anthony (Ed.). (2007). Minería, movimientos sociales y respuestas campesinas: una ecología política de transformaciones territoriales. Lima: Instituto de Estudios Peruanos y Centro Peruano de Estudios Sociales.

Borón, Atilio (2012). América Latina en la geopolítica del imperialismo. Buenos Aires: Ediciones Luxemburgo.

Bourdieu, Pierre (2014). Sobre el Estado: cursos en el Collège de France (19891929). Barcelona: Anagrama.

Centro de Investigación y Educación Popular (Cinep) (2012). Minería, conflictos sociales y violación de derechos humanos en Colombia. Bogotá.

Composto, Claudia y Navarro, Mina (Eds.). (2014). Territorios en disputa. Despojo capitalista, luchas en defensa de los bienes comunes naturales y al- 
ternativas emancipatorias para América Latina. México D. F.: Bajo Tierra Ediciones.

Contraloría General de la República (2012). Respuesta denuncia 2012-4608082111-OS y acumulados. Bogotá: Contraloría General de la República.

Corte Constitucional (2017). Sentencia SU-133/17 (p. 175). Bogotá.

Cubillos Quintero, León Felipe (2016). Los estudios socioculturales como estrategia académica para la comprensión de las problemáticas ambientales del territorio. Ambiente y Sostenibilidad, 5, 36-42.

Cypher, James (2009). ¿Vuelta al siglo XIX? el auge de las materias primas y el proceso de "primarización” en América Latina. Foro Internacional, XLIX, 119-162.

Defensoría del Pueblo (2010). La minería de hecho en Colombia. Bogotá: Defensoría del Pueblo.

Delgado Gómez, Paula (2015). La inversión extranjera en el sector agropecuario creció $241 \%$ desde 2010. La República.

Environmental Justice Organisations, Liabilities and Trade (EJOLT) (2016). Mapping environmental justice. Recuperado de http://www.ejolt.org

Escobar, Arturo (1998). La invención del Tercer Mundo: construcción y deconstrucción del desarrollo. Bogotá: Norma.

Escobar, Arturo (2008). Territories of difference: place, movements, life, redes. Durham: Duke University Press.

Escobar, Arturo; Álvarez, Sonia y Dagnino, Evelina (Eds.). (2001). Política cultural y cultura política: una nueva mirada sobre los movimientos sociales latinoamericanos. Bogotá: Taurus.

Escobar, Arturo y Pedrosa, Álvaro (Eds.). (1996). Pacífico: ¿desarrollo o diversidad? Estado, capital y movimientos sociales en el Pacífico colombiano. Bogotá: Cerec, Ecofondo.

Fierro Morales, Julio (2012). Políticas mineras en Colombia. Bogotá: Ilsa.

Gran Colombia Gold (2012). NI43-101 Mineral resource estimate on the Marmato Project, Colombia. Toronto. 
Grupo de Trabajo sobre Minería y Derechos Humanos en América Latina (2014). El impacto de la minería canadiense en América Latina y la responsabilidad de Canadá. Informe presentado a la Comisión Interamericana de Derechos Humanos. Washington: Fundación para el Debido Proceso.

Gudynas, Eduardo (2009). Diez tesis urgentes sobre el nuevo extractivismo. Contextos y demandas bajo el progresismo sudamericano actual. En Centro Andino de Acción Popular — CAAP- y Centro Latinoamericano de Ecología Social -Claes- (Eds.). Extractivismo, política y sociedad (pp. 187225). Quito: CAAP y Claes.

Gudynas, Eduardo (2011a). Debates sobre el desarrollo y sus alternativas en América Latina: Una breve guía heterodoxa. En M. Lang y E. Mokrani (Eds.). Más allá del desarrollo (pp. 21-53). Quito: Fundación Rosa Luxemburgo.

Gudynas, Eduardo (2011b). Más allá del nuevo extractivismo: transiciones sostenibles y alternativas al desarrollo. En F. Wanderley (Ed.), El desarrollo en cuestión: reflexiones desde América Latina (pp. 379-410). La Paz: CidesUmsa.

Harvey, David (2004). El “nuevo” imperialismo: acumulación por desposesión. Socialist Register, 99-129.

Idárraga, Andrés; Muñoz, Diego y Vélez, Hildebrando (2010). Conflictos socioambientales por la extracción minera en Colombia: casos de la inversión británica. Bogotá: Censat Agua Viva.

Laverde, Juan David y Medellín, María (2017). La protección de los mineros en uno de los pueblos más antiguos de Colombia. El Espectador, pp. 1-7.

Lefebvre, Henri (1974). La producción del espacio. París: Antropos.

Leff, Enrique (2012). Political Ecology -A Latin American Perspective. En Unesco-eolss Joint Committee (Ed.). Culture, Civilization and Human Society. Oxford: eolss Publishers.

Línea de Investigación en Estudios Socioculturales y Problemática Ambiental (IESPA) (2016). Problemáticas ambientales mineras desde la perspectiva sociocultural y derechos fundamentales. Pereira: Universidad Tecnológica de Pereira. 
Marini, Ruy Mauro (1991). Dialéctica de la dependencia. México: Era.

Martínez-Alier, Joan (2015). La ecología política y el movimiento global de justicia ambiental. Ecología Política, 50, 55-61.

Martínez-Alier, Joan; Temper, Leah; Del Bene, Daniela y Scheidel, Arnim. (2016). Is there a global environmental justice movement? The Journal of Peasant Studies, 43, 731-755.

Martínez-Alier, Joan y Walter, Mariana (2016). Social metabolism and conflicts over extractivism. En F. De Castro, B. Hogenboom, y M. Baud (Eds.). Environmental governance in Latin America (pp. 58-85). London: Palgrave Macmillan.

Observatorio de Conflictos Mineros de América Latina (Ocmal) (2017). Conflictos mineros en América Latina: extracción, saqueo y agresión. Estado de situación en 2016. Santiago: Ocmal.

O’Connor, James (2003). Desarrollo desigual y combinado y crisis ecológica. Ambiente \& Sociedad, 6, 9-23.

Osorio, Flor (2009). Territorialidades en suspenso. Desplazamiento forzado, identidades y resistencias. Bogotá: Codhes.

Pérez-Rincón, Mariano (2015). Conflictos ambientales en Colombia: actores generadores y mecanismos de resistencia comunitaria. Ecología Política, $48,76-82$.

Pérez-Rincón, Mariano; Sánchez Torres, Luis Darío y Zúñiga de Cardoso, María del Carmen (2014). Conflicto ambiental en el río Pance entre diversos usos y usuarios del agua. Cali: Universidad del Valle.

Petras, James y Veltmeyer, Henry (2017). The Progressive Cycle in Latin American Politics. En The class struggle in Latin America: making history today (pp. 59-78). London: Routledge.

Programa de las Naciones Unidas para el Medio Ambiente (PNUMA) (2013). Tendencias del flujo de materiales y productividad de recursos en América Latina. Ciudad de Panamá: Programa de las Naciones Unidas para el Medio Ambiente.

Ramírez, Francisco (2007). Tierra y minería, el conflicto en Colombia. Grupo Semillas, 32-36. 
Samaniego, Pablo; Vallejo, María Cristina y Martínez-Alier, Joan (2014). Déficit comercial y déficit físico en Sudamérica. Quito: Universidad Autónoma de Barcelona, Flacso.

Sarmiento, Libardo (2000). Conflicto, autonomía regional y socialismo ecológico. En S. Castañeda Roncancio, D. González Posso, y A. Mares M. (Eds.). Las claves territoriales de la guerra y la paz: desarrollo regional, participación ciudadana y agenda de paz (pp. 23-33). Santa Fe de Bogotá: Agenda Ciudadana por la Paz, la Vida y la Libertad.

Suárez Montoya, Aurelio (2013). La minería colonial del siglo XXI: no todo lo que brilla es oro. Bogotá: Ediciones Aurora.

Svampa, Maristella (2011). Modelo de desarrollo y la cuestión ambiental en América Latina: categorías y escenarios en disputa. En F. Wanderley (Ed.). El desarrollo en cuestión: reflexiones desde América Latina (Primera edición en español, pp. 411-444). La Paz: Cides-Umsa.

Tetreault, Darcy (2014). Megaminería en México, ¿Un camino hacia el desarrollo local y nacional? Estudios Críticos del Desarrollo, IV, 101-130.

Tetreault, Darcy (2016). Tres formas de ecología política. En G. González, H. Márquez, y R. Soto (Eds.), Privatización de los bienes comunes. Discusiones en torno a la sustentabilidad, precarización y movimientos sociales (pp. 13-34). Zacatecas: Miguel Ángel Porrúa.

Toro, Catalina (2012). Geopolítica energética: minería, territorio y resistencias sociales. En C. Toro, J. Fierro, S. Coronado, y T. Roa (Eds.). Minería, territorio y conflicto en Colombia (pp. 13-38). Bogotá: Universidad Nacional de Colombia.

Veltmeyer, Henry (2003). La búsqueda de un desarrollo alternativo. En L. R. Morán Quiroz, H. Veltmeyer y A. O’Malley (Eds.). En contra del neoliberalismo: el desarrollo en la comunidad en América Latina. México: Universidad Autónoma de Zacatecas, Miguel Ángel Porrúa.

Veltmeyer, Henry (2013). Economía política de la extracción de recursos naturales: ¿Nuevo modelo de desarrollo o imperialismo extractivo? Estudios críticos del desarrollo, III, 9-43. 